American J. of Engineering and Applied Sciences 1 (1): 1-6, 2008

ISSN 1941-7020

(C) 2008 Science Publications

\title{
Closed Die Forging Geometrical Parameters Optimization for Al-MMC
}

\author{
${ }^{1}$ M. Jolgaf, ${ }^{2}$ S.B. Sulaiman, ${ }^{2}$ M.K.A. Ariffin and ${ }^{2}$ A.A. Faieza \\ ${ }^{1}$ ITMA, University Putra Malaysia, 43400 UPM Serdang, Selangor, Malaysia \\ ${ }^{2}$ Faculty of Engineering, University Putra Malaysia, 43400 \\ UPM Serdang, Selangor, Malaysia
}

\begin{abstract}
Demand for lighter and stiffer products has been increasing in the last few years especially in automobile manufacturing. The closed die forging process of Metal Matrix Material (MMC) is presented as possible solution, since it produces parts with good mechanical properties and lighter weight. A computational modeling of closed die forging process using finite element method and optimization techniques makes the design optimization faster and more efficient, decreasing the use of conventional trial and error methods. In this study, the application of commercial finite element software (ANSYS) has been used to model cold closed die forging process. The model has been developed using ANSYS Parametric Design Language (APDL) to simulate a single stage axisymmetry closed die forging process for $\mathrm{H}$ cross sectional shape. The material used is AlMgSi matrix with $15 \% \mathrm{SiC}$ particles. Its flow curve and fractural strain are obtained from the literature. ANSYS Optimizer is used to obtain the maximum height in which the material can flow in the rib by changing Design Variables (DV) and State Variables (SV). Normally design variables are geometrical parameters such as, rib height to width ratio, web height to rib height ratio, fillet radii, draft angle and billet radius. State Variables (SV) are some parameters that depend on the design variables such as, the equivalent strain which must be below the fracture strain of the MMC material, and an acceptable contact gap (within the allowable tolerances range). Optimization method called Sub-Problem Approximation Method was used to find out the optimal design set. The technique used in this study can be used for newly developed materials to investigate its forgeability for much complicated shapes in closed die forging process.
\end{abstract}

Key words: Closed die forging, finite element methods, optimization

\section{INTRODUCTION}

As oil prices are going high, a strong pressure for weight reduction in car and aircraft fabrication urges the optimization of the design of products employing low weight materials ${ }^{[1]}$. Aluminum based metal matrix composites (Al-MMCs) are replacing the conventional materials because they exhibit lighter weight and sufficient stiffness and strength, which make them very good candidates for automotive applications ${ }^{[2,3]}$. Closed die forging is the main metal forming process for the mass-production of middle-size or small forging parts $^{[0]}$.

Finite element methods and optimization techniques of closed die forging process is still of considerable interest. There are many objectives for these techniques, for example, material flow behavior, fold-over, improper die filling, tool wear and excessive forging loads, especially with a new materials emerging every day with very attractive properties to automobile and aerospace engineering. It is very important to study the flow behavior of these materials to produce defect less closed die forging products. A circular $\mathrm{H}$ shape part as shown in Fig. 1 was selected to conduct the finite element simulation and process optimization.

One of the primary tasks of forging design procedure is a conversion of the available machined part data, into forged part data. In process of conversion, a necessary forging cavity, corners and fillet radii and appropriate draft angles are added to the machined part cross-section ${ }^{[5]}$. The main factors effecting the material flow deformation are die shape, material properties, billet height/diameter ratio, and frictional condition at the billet/die interface ${ }^{[4]}$.

APDL is a scripting language that can be used to build the model in terms of parameters (variables). The APDL is used to build the model in a parametric form to enable changing these parameters in the optimization process, so that the optimal die and billet shapes are obtained. The Design Variables (DVs) are the billet

Corresponding Author: Mohamed Jolgaf, Institute of Advanced Technology, Universiti Putra Malaysia, 43400 UPM Serdang, Selangor, Malaysia TEL: +60163966384 
radius, the rib height/width ratio, fillet radii (FR1, FR2) and draft angle $(\theta)$. The equivalent strain and the contact gap are given as a State Variable (SV). The state variables are working as constrain in the optimization process, forcing the design parameters to be adjusted in order to have a strain not higher than the fractural strain as shown in Fig. 2, and a contact gap not greater than the allowable tolerance of the forged part. The Fractural strain is obtained from the literature ${ }^{[6]}$, which is 1.05 at $20^{\circ} \mathrm{C}$. The objective function, which is going to be minimized by ANSYS optimization module, is shown in Fig. 7.

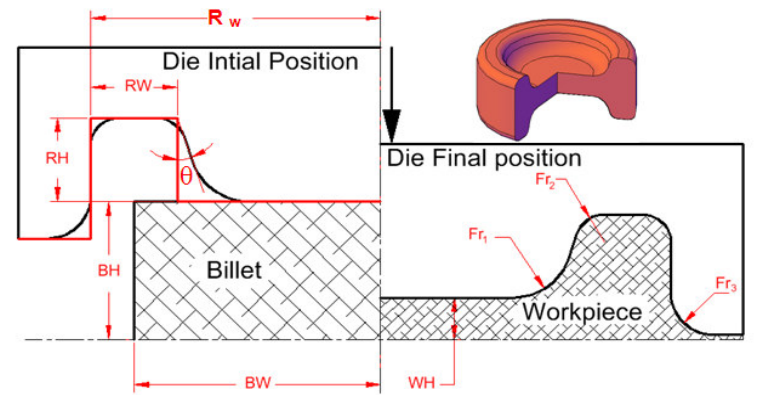

Fig. 1: Configuration of billet and die before and after forging

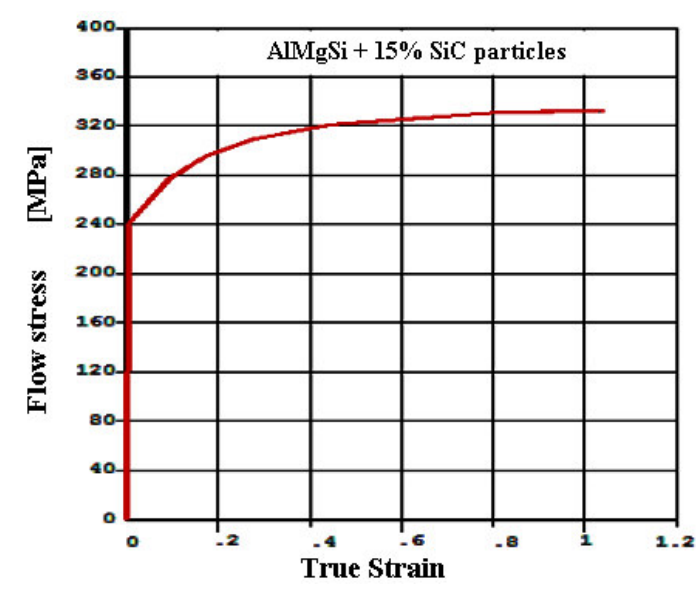

Fig. 2: Flow curve of AlMgSi+15\% SiC particles ${ }^{[6]}$

\section{METAL MATRIX COMPOSITES}

Metal-matrix composites, in general, consist of at-least two components, one is metal matrix and the second component is reinforcement. The matrix is a metal in all cases, but a pure metal is rarely used as the matrix, it is generally an alloy. In the production of the composite, the matrix and the reinforcement are mixed together.

Aluminum is the most attractive non-ferrous matrix material used particularly in the aerospace and automotive industry where weight of structural components is crucial. Three types of reinforcement are used in MMC; particulate, short fibers and long fibers as shown in Fig. 3. The MMC material used in the simulation is $\mathrm{AlMgSi}$ matrix with $15 \% \mathrm{SiC}$ particles which has a reasonable ductility (strain limit $\varepsilon=1.05)^{[6]}$.
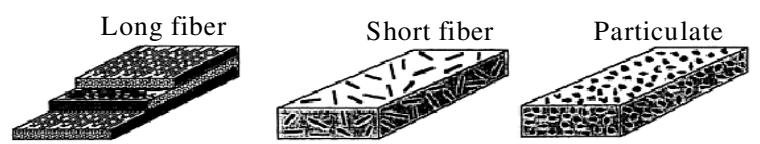

Fig. 3: Types of reinforcement in $\mathrm{MMCs}^{[7]}$

Forging MMCs cause particle and fiber breakage, and normally result in cracks at the outer surface of the billet $^{[6,8]}$. To avoid fibers and particles breakage which lead to cracks, the equivalent strain of the material must be kept lower than the fractural strain obtained from the literature which is $\varepsilon=1.05^{[6]}$. The fractural strain is used in the optimization process as a state variable maximum limit.

\section{FINITE ELEMENT MODEL}

The die cavity shape is represented with straight lines with an initial rib height/width ratio (RH/RW) then initial draft angle $(\theta)$ and fillet radii ( Fr1, Fr2, Fr3), are added to get the die profile as shown in Fig. 4, which is going to be modified until the optimal die shape is obtained for the selected material. The billet is represented with initial radius and then the height is calculated based on the volume of the die cavity, because the die cavity is changing during the optimization loops due to changing the design variables. The initial billet is represented with geometrical model consisting of assemblage of finite element. Equations relating the distribution of forces and displacements of the metal are established and the boundary condition and die movement are imposed.

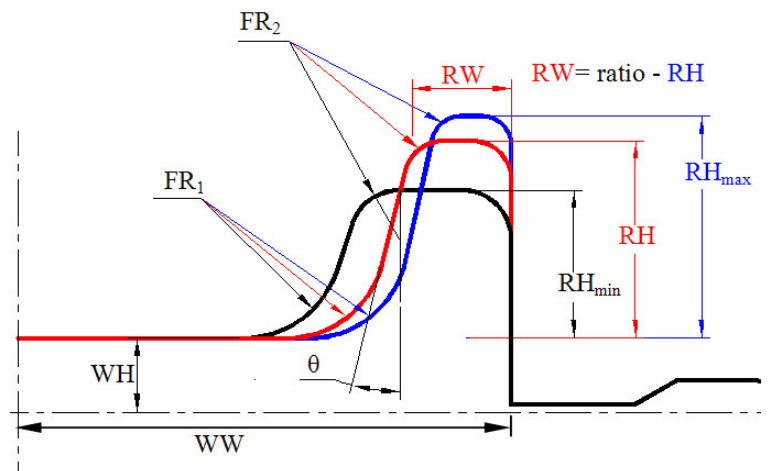

Fig. 4: The shapes of $1 / 2$ of the upper die 
The components of the model are shown in Fig. 5. The cylindrical billet is made of $\mathrm{AlMgSi}$ reinforced with $15 \% \mathrm{SiC}$ particles $(\mathrm{AlMgSi}+15 \% \mathrm{SiC})$ and has an initial radius of $16 \mathrm{~mm}$, just a quarter of the billet and the die being considered for the analysis to reduce computational time and cost. Three types of elements are used in the model. The billet is built up of two dimensional 4-node viscoplastic solid elements (ANSYS type VISCO106). A rigid to flexible contact pair with a pilot node (Node no. 6) is used to represents die/billet contact. A two dimensional 2-node surface-tosurface contact is used to represent friction and sliding contact for the deformable surface of billet (ANSYS type CONTA171) and a two dimensional target element is used to model the rigid surface of the die (ANSYS type TARGE169), the boundary condition of the die surface follow the boundary condition imposed on the pilot node.

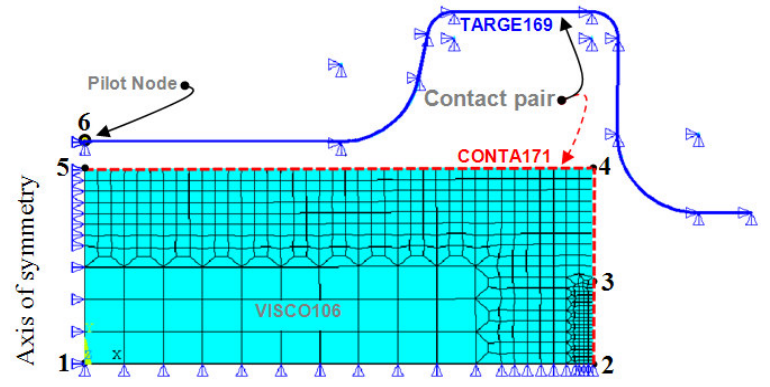

Fig. 5: The discretised model showing boundary condition

The axis of symmetry (line 1-5) of the model is fixed in $\mathrm{X}$ direction including the pilot node (node6). The bottom line of the billet (line 1-2) is fixed in Y direction. A displacement load is applied on the pilot node (node6) in negative $\mathrm{Y}$ direction. The target elements (TARGE169) will be subjected to the same load and boundary condition of the pilot node associated to these elements by default ${ }^{[9]}$.

Since forging process is associated with large strain, deformation and shape changing, it is hard to obtain a stress distribution, which equilibrates a given set of external load. As a result the total load is applied in a number of increments. During each increment, a linear prediction of nonlinear response is made, and subsequent iterative corrections are performed in order to restore equilibrium by elimination of the residual forces. It is necessary to activate geometrical nonlinearity option (NLGEOM) in order to update the geometry in each increment (sub-step). In ANSYS, the non-linear solution is based on the Newton-Raphson procedure $^{[9]}$.

\section{THE OPTIMIZATION MODULE}

The goal of the optimization process is to find the best solution for the given problem in the design space defined to the optimization algorithm. Formulation of the problem should offer sufficient design space to the searching algorithm used in optimization process. Optimization model contains of three components: design variable (independent variable), constraints (state variables or dependent variables) and the objective function (dependent variable to be minimized). Specifying the lower and the upper limits of the design variables and identify the design space by specifying the constraints (a dependent variable value that shouldn't be exceeded). After the design space is defined the optimization algorithm will search in design space for the minimum objective function.

Design variables (independent variables): One of the most important design variables is the rib height to width ratio, the height is defined as a Design variable with an initial value $(4 \mathrm{~mm})$ and the rib width is defined as a function of the rib height, also the web height is defined as a variable. Then the billet radius, the die fillet radii, and the draft angles are also defined as design variables

$$
\begin{aligned}
& \text { Rib Height }=4 \mathrm{~mm} \\
& \text { Rib ratio= Rib (Height/Width) }
\end{aligned}
$$

The optimization algorithm will search for the minimum objective function (maximum height that the forged material can reach in the rib) with in the design space specified by the upper and the lower limits of the design and state variables.

In the optimization procedure, ANSYS optimization module performs a series of analysisevaluation-modification cycles. That is, an analysis of the initial design is performed, the results are evaluated against specified design parameters, and the design is modified as necessary. The process is repeated until all specified criteria are $\operatorname{met}^{[9]}$.

Constraints (dependent variables): Aluminum metal matrix composites has low ductility compared to traditional forging materials. Therefore, it is very important to specify the fracture strain as a constraint for optimization algorithm to avoid cracked forgings. Any gap between the die and the forged part is undesirable, and it is either due to incomplete filling at the corner radii, or due to fold-over or wrinkles as shown in Fig. 6. ANSYS facilitates measuring the contact gap between the contact pairs. This gap is also, 
defined as constraint to the optimization algorithm. It is up to the designer to set the maximum and minimum limit, depending upon the tolerances of the forged part. Parts with lose tolerances may have wide range.
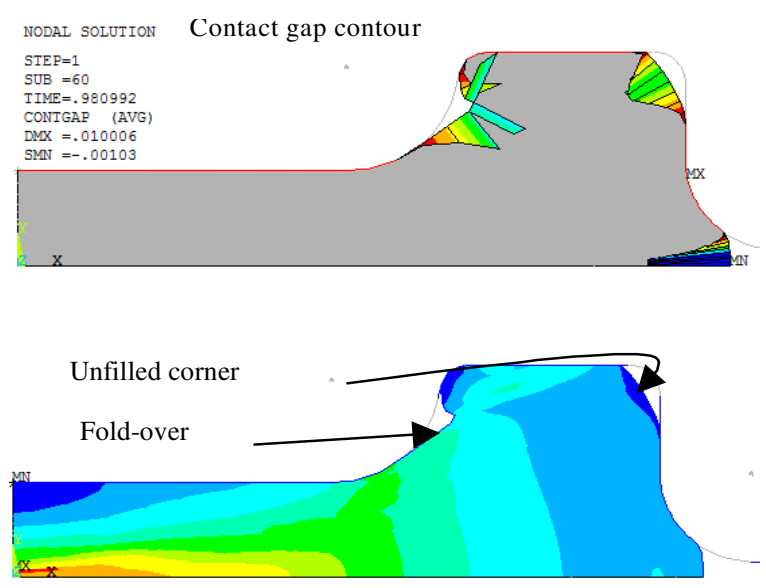

Fig. 6: Contact gap is given as a state variable

Objective function: In closed die forging, complete die filling with out defects such as fold-over and wrinkles is the main objective. In this study, the flow of the selected material in the rib cavity is going to be checked and the aim of this simulation is to find out the maximum height that the material can flow in the rib. Since the rib height cannot be given as an objective function because it is a design variable. Therefore, the difference in the height of the forged part (with minus sign) is given as objective function as shown in Fig. 7. ANSYS optimization module is only minimizing the objective function, while in this study the goal is to maximize metal flow in the rib, that's why the minus sign is added.

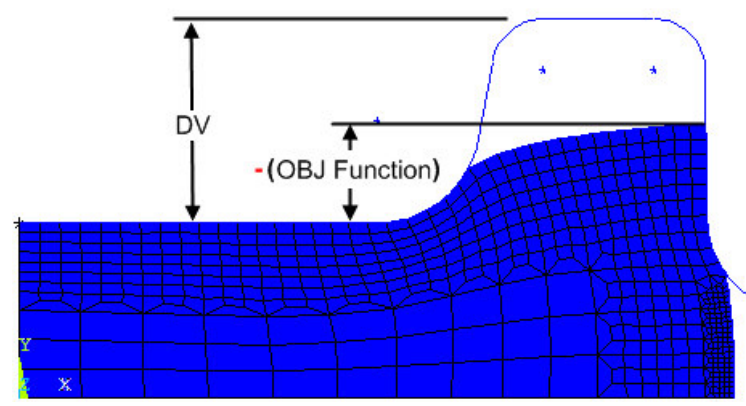

Fig. 7: The objective function

\section{RESULTS AND DISCUSSION}

The aim of this work is to shape defect less products made of the selected material using closed die forging process.

Load displacement curve for the optimal design set obtained form the simulation is shown in Fig. 8. Forging load increases gradually until the beginning of the flash formation, after that it starts increasing sharply due to the increase of the flow resistance at the flash region. This resistance, force the material to fill the die cavity.

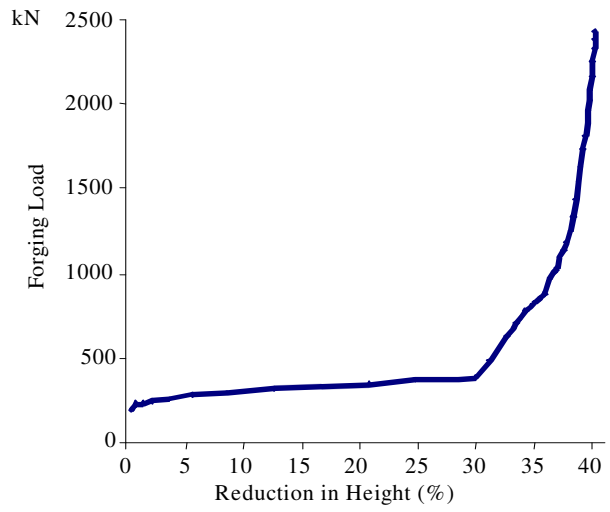

Fig. 8: Load displacement curve

Maximum strain that the material $\mathrm{AlMgSi}+15 \% \mathrm{SiC}$ can sustain with out fracture is equal to (1.05). The strain distribution for optimal (best visible) and invisible design sets is shown in Fig. 9. Their maximum strain values are 1.006 and 1.352 respectively.

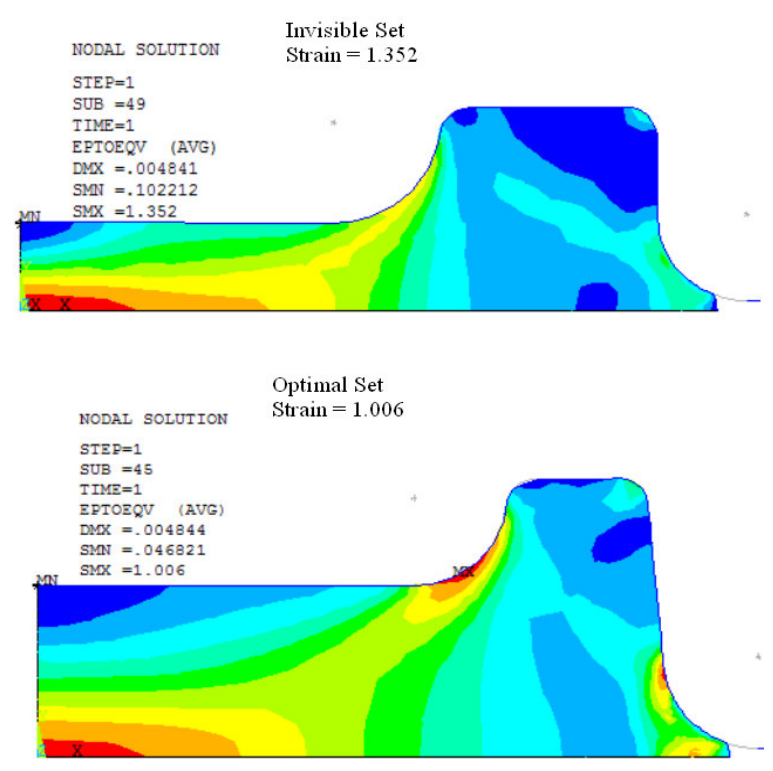

Fig. 9: Equivalent strain distribution 
The optimization module is searching for the minimum objective function within the specified limits of the state variables. Fig. 10 shows how the objective function is being minimized by changing the design variables, and the equivalent strain is also plotted in order to show how is the optimization module is going towards a save equivalent strain $(\varepsilon<1.05)$.

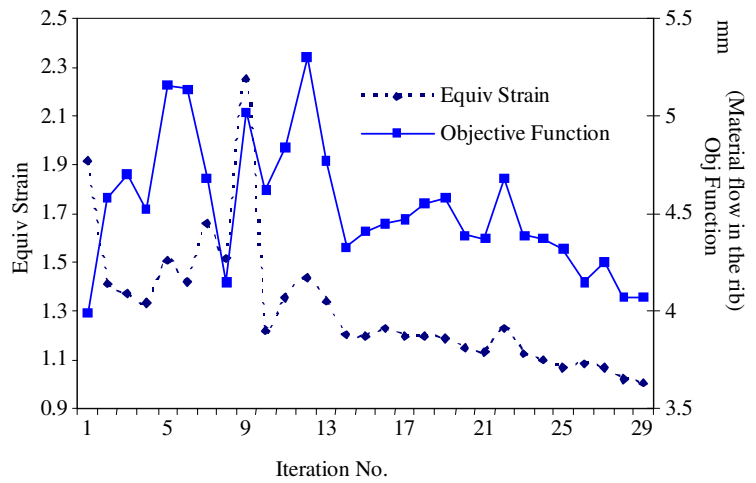

Fig. 10: The equivalent strain and objective function vs. Optimization iteration number

Effect of the design variable (billet radius) on the equivalent strain is shown in Fig. 11, and it can be seen that while the optimization module is searching for a minimum objective function, the billet radius is increasing to force the strain value towards a value lower than the fractural strain.

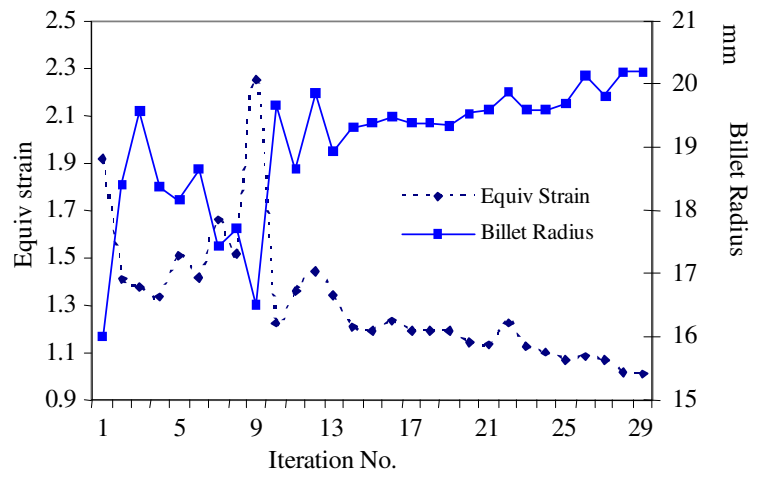

Fig. 11: The equivalent strain and billet radius vs. Optimization iteration number

In closed die forging process, there are two types of material flow deformation, upsetting and extrusion, which are controlled by the profile of the die cavity. The volume of the die cavity to be filed by displacing billet material by upsetting is constrained by the billet radius and the maximum equivalent fractural strain. The displaced billet volume is shown in Fig. 12. As the ratio of the volume of the rib to the volume of the billet is bigger, the closed die forging process is constrained by upsetting more than the extrusion and vice versa.

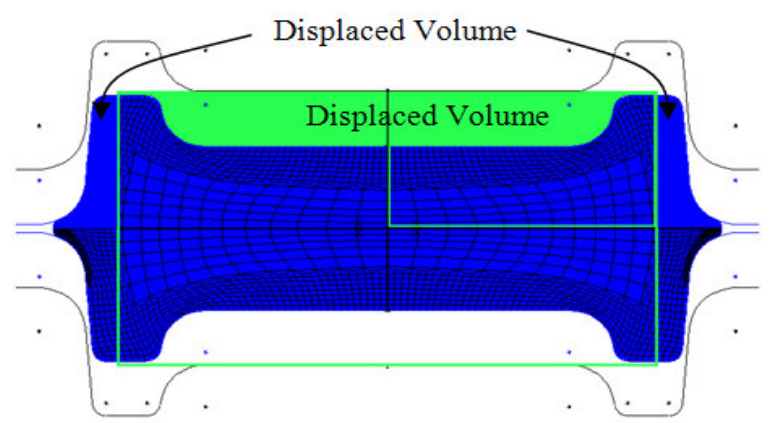

Fig. 12: Deformed mesh final stage and displaced volume

Table (1): List of visible and invisible design sets

\begin{tabular}{|c|c|c|c|}
\hline & $\begin{array}{l}\text { Set } 1 \\
\text { (Infeasible) }\end{array}$ & $\begin{array}{l}\text { Set } 2 \\
\text { (Infeasible) }\end{array}$ & $\begin{array}{l}\text { Set } 4 \\
\text { (Infeasible) }\end{array}$ \\
\hline Eqvstn (SV) & $>1.9163$ & $>1.4098$ & $>1.3326$ \\
\hline Fover (SV) & $0.93119 \mathrm{E}-04$ & $0.36326 \mathrm{E}-04$ & $>0.19901 \mathrm{E}-03$ \\
\hline Theta (DV) & 12.000 & 14.542 & 14.085 \\
\hline FL1 (DV) & $0.35000 \mathrm{E}-02$ & $0.32286 \mathrm{E}-02$ & $0.30350 \mathrm{E}-02$ \\
\hline RH (DV) & $0.40000 \mathrm{E}-02$ & $0.45820 \mathrm{E}-02$ & $0.45209 \mathrm{E}-02$ \\
\hline Ratio (DV) & $0.90000 \mathrm{E}-02$ & $0.93847 \mathrm{E}-02$ & $0.82249 \mathrm{E}-02$ \\
\hline Radius (DV) & $0.16000 \mathrm{E}-01$ & $0.18419 \mathrm{E}-01$ & $0.18384 \mathrm{E}-01$ \\
\hline WH (DV) & $0.40000 \mathrm{E}-02$ & $0.55448 \mathrm{E}-02$ & $0.64737 \mathrm{E}-02$ \\
\hline \multirow[t]{2}{*}{ Ydis (OBJ) } & $-0.39874 \mathrm{E}-02$ & $-0.45775 \mathrm{E}-02$ & $-0.45233 \mathrm{E}-02$ \\
\hline & $\begin{array}{l}\text { Set } 13 \\
\text { (Infeasible) }\end{array}$ & $\begin{array}{l}\text { Set } 14 \\
\text { (Infeasible) }\end{array}$ & $\begin{array}{l}\text { Set } 16 \\
\text { (Infeasible) }\end{array}$ \\
\hline Eqvstn (SV) & $>1.3388$ & $>1.2064$ & $>1.2315$ \\
\hline Fover (SV) & $0.58636 \mathrm{E}-04$ & $0.14937 \mathrm{E}-04$ & $0.36727 \mathrm{E}-04$ \\
\hline Theta (DV) & 14.405 & 14.833 & 14.207 \\
\hline FL1 (DV) & $0.32655 \mathrm{E}-02$ & $0.32550 \mathrm{E}-02$ & $0.32552 \mathrm{E}-02$ \\
\hline RH (DV) & $0.47799 \mathrm{E}-02$ & $0.43315 \mathrm{E}-02$ & $0.44554 \mathrm{E}-02$ \\
\hline Ratio (DV) & $0.93918 \mathrm{E}-02$ & $0.93831 \mathrm{E}-02$ & $0.98974 \mathrm{E}-02$ \\
\hline Radius (DV) & $0.18935 \mathrm{E}-01$ & $0.19314 \mathrm{E}-01$ & $0.19472 \mathrm{E}-01$ \\
\hline WH (DV) & $0.60120 \mathrm{E}-02$ & $0.63624 \mathrm{E}-02$ & $0.60839 \mathrm{E}-02$ \\
\hline \multirow[t]{2}{*}{ Ydis $(\mathrm{OBJ})$} & $-0.47733 \mathrm{E}-02$ & $-0.43292 \mathrm{E}-02$ & $-0.44523 \mathrm{E}-02$ \\
\hline & $\begin{array}{l}\text { Set } 25 \\
\text { (Infeasible) }\end{array}$ & $\begin{array}{l}\text { Set } 26 \\
\text { (Infeasible) }\end{array}$ & $\begin{array}{l}\text { Set } 28 \\
\text { (Feasible) }\end{array}$ \\
\hline Eqvstn (SV) & $>1.0676$ & $>1.0814$ & 1.0190 \\
\hline Fover (SV) & $0.52318 \mathrm{E}-04$ & $0.71409 \mathrm{E}-04$ & $0.63430 \mathrm{E}-04$ \\
\hline Theta (DV) & 12.376 & 12.140 & 12.095 \\
\hline FL1 (DV) & $0.34776 \mathrm{e}-02$ & $0.31241 \mathrm{E}-02$ & $0.33441 \mathrm{E}-02$ \\
\hline RH (DV) & $0.43242 \mathrm{E}-02$ & $0.41379 \mathrm{E}-02$ & $0.40599 \mathrm{E}-02$ \\
\hline Ratio (DV) & $0.89505 \mathrm{E}-02$ & $0.86793 \mathrm{E}-02$ & $0.88614 \mathrm{E}-02$ \\
\hline Radius (DV) & $0.19700 \mathrm{E}-01$ & $0.20134 \mathrm{E}-01$ & $0.20196 \mathrm{E}-01$ \\
\hline WH (DV) & $0.64909 \mathrm{E}-02$ & $0.64897 \mathrm{E}-02$ & $0.64945 \mathrm{E}-02$ \\
\hline \multirow[t]{2}{*}{ Ydis (OBJ) } & $-0.43204 \mathrm{E}-02$ & $-0.41515 \mathrm{E}-02$ & $-0.40661 \mathrm{E}-02$ \\
\hline & $\begin{array}{l}\text { *Set 29* } \\
\text { (Feasible) }\end{array}$ & & \\
\hline Eqvstn (SV) & 1.0056 & & \\
\hline Fover (SV) & $0.67477 \mathrm{E}-04$ & & \\
\hline Theta (DV) & 12.280 & & \\
\hline FL1 (DV) & $0.33440 \mathrm{E}-02$ & & \\
\hline RH (DV) & $0.40605 \mathrm{E}-02$ & & \\
\hline Ratio (DV) & $0.88496 \mathrm{E}-02$ & & \\
\hline Radius (DV) & $0.20194 \mathrm{E}-01$ & & \\
\hline WH (DV) & $0.64969 \mathrm{e}-02$ & & \\
\hline Ydis $(\mathrm{OBJ})$ & $-0.40665 \mathrm{E}-02$ & & \\
\hline Eqvstn: & \multicolumn{3}{|c|}{ The equivalent strain, must be not more than 1.05} \\
\hline Fover: & \multicolumn{3}{|c|}{ The unfilled distance between the die and the forged part } \\
\hline Theta: & \multicolumn{3}{|c|}{ The draft angle } \\
\hline FL1: & \multicolumn{3}{|l|}{ The fillet radius } \\
\hline RH: & \multicolumn{3}{|l|}{ The rib height } \\
\hline Ratio: & \multicolumn{3}{|c|}{ A number that control the rib height to width ration } \\
\hline Radius: & \multicolumn{3}{|c|}{ The billet radius } \\
\hline WH: & \multicolumn{3}{|l|}{ The web height } \\
\hline
\end{tabular}


Table 1 shows the list of design, state variables and objective functions for all design sets obtained during the optimization iterations. Design sets that have $(>)$ signs at any state variables is considered invisible, because the value of that variable is out of the design space (limits specified for that variable).

\section{CONCLUSION}

In this work, closed die forging process of $\mathrm{AlMgSi}$ matrix with $15 \% \mathrm{SiC}$ particles was simulated using commercial finite element software (called ANSYS) to investigate the material flow behavior and to predict the forging load and the strain distribution. The forging process was optimized using ANSYS optimization module. The optimization process was conducted in a selected design space, which is defined by intervals of some geometrical variables and state variables in order to find out visible design sets and select the best set based on minimization of the objective function.

Finite element analysis in conjunction with optimization techniques, are used to develop a system for the design of optimal die shape of closed die forging process. The finite element model was built parametrically using ANSYS Parametric Design Language. The optimization module uses the analysis file to search for the optimal die and billet shapes by changing the geometrical parameters (design variables) keeping the state variables within the specified limits. The targeted axi-symmetric (H) shape is obtained in a single stage forming with the dimension listed in the best visible design set (*set 29*) in Table 1. Performing this task wouldn't be easy with out combining the finite element analysis and the optimization techniques.

\section{ACKNOWLEDGMENTS}

The authors would like to thank the Institute of Advanced Technology and Universiti Putra Malaysia for their cooperation and the facilities provided.

\section{REFERENCES}

1. Cavaliere, P., 2004. Isothermal forging of AA2618 reinforced with $20 \%$ of alumina particles, Composites: Part A 35: 619-629. DOI: 10.1016/j.compositesa.2004.02.014.

2. Prasada, S.V. and R. Asthana, 2004. Aluminum metal-matrix composites for automotive applications: Tribological considerations, Tribology Lett., 17: 445-453. DOI: 10.1023/B:TRIL.0000044492.91991.f3.

3. Cavaliere, P., 2007. Flow curve prediction of an Al-MMC under hot working conditions using neural networks, Comput. Mater. Sci, 38: 722-726. DOI: 10.1016/j.commatsci.2006.05.002.

4. Wu, C.Y. and Y.-C Hsu, 2002. Optimal shape design of an extrusion-forging die using a polynomial network and genetic algorithm, Int. J. Adv. Manuf. Technol, 20:128-137. DOI: $10.1007 / \mathrm{s} 001700200134$

5. Jolgaf, M., A.M.S. Hamouda, S.B. Sulaiman and M.M. Hamdan, 2002. Development of a CAD/CAM system for the closed-die forging process, Int. J. Adv. Manuf. Technol, 20: 128-137. DOI: 10.1016/S0924-0136(03)00113-4

6. Wagener, H.W. and J. Wolf, 1993. Cold forging of mmcs of aluminum alloy matrix, J. Mater. Proc. Technol., 37: 253-265.

DOI: 10.1016/0924-0136(93)90095-N

7. Daniel B. Miracle and Steven L. Donaldson, 2001. Introduction to Composites. In: ASM Handbook, Volume 21: Composites. ASM International.

8. Jiang, J. and B. Dodd, 1995. Workability of aluminum-based metal matrix composites in cold compression, Composites, 26: 62-66. .

DOI: 10.1016/0010-4361(94)P3631-A

9. ANSYS, Inc., 2005. ANSYS Release 10.0 documentation. ANSYS, Inc., Canonsburg, PA 15317, USA. 